\title{
The role of mitochondrial ATP-sensitive potassium channels on cardiovascular effects of thiopental and ketamine in rats
}

\author{
Altunkaynak HO, Tecder-Unal M \\ Department of Pharmacology, Faculty of Medicine, Baskent University, Ankara, Turkey. mugetecder@yahoo.com
}

\begin{abstract}
OBJECTIVE: We aimed to investigate whether mitochondrial ATP-sensitive potassium ( mitoK $_{\text {ATP }}$ ) channels play any role on cardiovascular effects of thiopental (TP) or ketamine $(K)$ anesthesia in rats.

BACKGROUND: mitoK $_{\text {ATP }}$ channels are the end-effectors of cardioprotection induced by some anesthetics. TP and K are the most frequently used anesthetics with their own cardiovascular effects in experimental studies. To the best of our knowledge, there is no study investigating the cardiovascular effects of TP and K associated with mitoK ${ }_{\text {ATP }}$ channels. MATERIALS AND METHODS: The experimental groups: TP control, K/Xylazine (X) control, TP+5-hydroxydecanoate (5-HD; mitoK ${ }_{A T P}$ channel blocker) and K/X+5-HD. Mean arterial blood pressure (MABP), heart rate (HR) and standard limb lead II ECG were recorded and arrhythmia parameters were evaluated.

RESULTS: Blockage of mitoK ${ }_{\text {ATP }}$ channels by $5-\mathrm{HD}$ increased MABP and decreased HR in the TP+5-HD and K/ $X+5-H D$ groups, respectively. 5-HD caused an increase in ventricular ectopic beat (VEB) incidence. Moreover, VEB incidence was significantly different in TP+5-HD (100\%) than K/X+5-HDgroup (66.6\%) and ventricular tachycardia was only seen in TP+5-HD (incidence was $88.3 \%$ ).

CONCLUSION: mitoK $_{\text {ATP }}$ channels play different roles in influencing cardiovascular effects of K/X and TP anesthesia in rats. The differences in hemodynamic parameters and arrhythmia scores of these anesthetics should be considered when they are used in an experimental study associated with mitoK $_{\text {ATP }}$ channels (Fig. 3, Ref. 35). Text in PDF www.elis.sk. KEYWORDS: 5-hydroxydecanoate, thiopental, ketamine/xylazine, mean arterial blood pressure, heart rate, arrhythmia.
\end{abstract}

\section{Introduction}

Anesthesia is an essential part of the surgical process that removes sensory functions temporarily, depresses the nervous system and so causes blackout of consciousness. In experimental animals, anesthetics are being widely used to prevent sensation of fear and pain of animals associated with surgical procedure, protect the researcher and provide safely and an easy surgical approach. The purpose of the experiment, type and duration of the surgical procedure, species of the animal, experience of the researcher are the main factors when choosing the anesthetic. However, anesthetics can effect a great number of organ systems, so choosing the anesthetic has a great impact on the experimental protocol (1).

Thiopental (TP) is the most frequently used barbiturate as a general anesthetic in experimental animals. Although TP could

Department of Pharmacology, Faculty of Medicine, Baskent University, Ankara, Turkey

Address for correspondence: M. Tecder-Unal, MD, PhD, Department of Pharmacology, Faculty of Medicine, Baskent University, Baglica Campus, Etimesgut, Ankara, Turkey.

Phone: +90.312 .2466679 , Fax: +90.312.2466689

Acknowledgements: This study was supported by Baskent University Research Fund (DA 10/11). We thank the Baskent University Medical Faculty students: Melike Yardimci, Arda Erdut, Resul Bircan, Halis Dogukan Ozkan and Baskent University Experimental Animals Production and Research Center Unit (especially Veterinary Medicine Didem Bacanli, Health Technician Adem Kurtcuoglu, Sanitary Servant Sezai Kolcuk and Omer Ceylan) for their contributions. reduce blood pressure and cardiac contractility, it does not cause severe arrhythmia. So TP is preferred especially in designing experiments associated with cardiovascular system. Ketamine (K) is frequently used as a parenteral dissociative anesthetic without its visceral analgesic effect. Ketamine anesthesia increases heart rate, systemic blood pressure, pulmonary

arterial pressure and cardiac output (2). Xylazine (X), an $\alpha_{2}-$ adrenoceptor agonist, has sedative and analgesic effects but it is not accepted as a general anesthetic. Addition of X to $\mathrm{K}$ anesthesia is frequently used to eliminate the undesirable effects (delirium, increase of secretion) of $\mathrm{K}$.

ATP-sensitive potassium $\left(\mathrm{K}_{\text {ATP }}\right)$ channels were isolated from different tissues, e.g. ventricle myocytes, brain, smooth muscle, skeletal muscle and pancreas. It has been reported that opening of the myocardial $\mathrm{K}_{\text {ATP }}$ channels is an endogenous protective mechanism against ischemic injury (3) and also mediates protective effects of ischemic- or anesthetic-induced preconditioning $(4,5)$. In addition to sarcolemmal $\mathrm{K}_{\text {ATP }}$ channels, activation of mitochondrial $\mathrm{K}_{\text {ATP }}\left(\right.$ mitoK $\left._{\mathrm{ATP}}\right)$ channels which are located on mitochondrial inner membrane, is involved as a trigger in ischemic preconditioning/cardio-protection by different subcellular mechanisms (6). The opening of mitoK ${ }_{\text {ATP }}$ channels induces an increase in $\mathrm{K}^{+}$current, that is enough to change the mitochondrial volume without an important depolarization of the membrane $(7,8)$. It is suggested that changing the volume of mitochondria has important effects on cell energy coupling. This mild depolarization of the mitochondrial membrane potential by opening mitoK $_{\text {ATP }}$ channels 


\section{$567-570$}

also limits mitochondrial $\mathrm{Ca}^{2+}$ loading by decreasing the driving force for $\mathrm{Ca}^{2+}$ influx (9).

5-hydroxydecanoate (5-HD) blocks selectively mitoK $_{\text {ATP }}$ channels (10-12) and in this way it may attenuate the ischemic or pharmacological preconditioning of the heart. Although there are some studies which suggest that 5-HD blocks also the sarcolemmal $\mathrm{K}_{\text {ATP }}$ channels, it is also known that 5-HD is much more potent on mitoK $\mathrm{ATP}_{\text {AT }}$ channels $(13,14)$.

The mitoK ${ }_{\text {ATP }}$ channels are the end-effectors of the cardioprotection of volatile anesthetics $(5,9)$. TP and $\mathrm{K}$ are the most frequently used anesthetics with their own cardiovascular effects in experimental studies. But there is no study investigating the cardiovascular effects of TP and $\mathrm{K}$ associated with mitoK $\mathrm{K}_{\text {ATP }}$ channels. So the aim of the present study was to investigate whether mitoK $_{\text {ATP }}$ channels play any role on cardiovascular effects of thiopental (TP) or ketamine $(\mathrm{K})$ anesthesia in rats.

\section{Materials and methods}

This study was approved by the Baskent University Ethical Committee for Experimental Research on Animals (DA 10/11). All experiments were performed on male Wistar Albino rats $(n=22$, $250-450 \mathrm{~g}$ ). The rats were housed in cages at room temperature $21 \pm 1{ }^{\circ} \mathrm{C}$, under $12 / 12$ hours light/dark cycle and were allowed "ad libitum" access to standard laboratory diet and tap water. In anesthetized animals tracheotomy was performed and they were mechanically ventilated with room air with the help of the animal ventilator (Rodent Ventilator 7025 UgoBasile, $5 \mathrm{~mL} / 100$ g, 34 pulse/min room air). Body temperature of the experimental animals was maintained at $37 \pm 1{ }^{\circ} \mathrm{C}$. A standard limb lead II electrocardiogram (ECG) and heart rate were continuously monitored and recorded throughout the experiment, using electrocardiograph (ECG 100B; Biopac. System Inc.) and a computerized data acquisition system. After the right jugular vein cannulation, saline $(0.8 \mathrm{~mL} / \mathrm{h})$ was continually administered during the experiments with an infusion pump (JMS SP-100s). The left carotid artery was cannulated with a heparinized saline filled catheter connected to a pressure transducer (MAY GTA200) for arterial blood pressure monitoring. After all the surgical procedures had been performed, related records were monitored and saved during the 10-minute period through MP100 system (Biopac Systems, Inc.). At the end of the experimental protocol, the rats were sacrificed with a high dose anesthetic.

The study animals were divided into groups as follows:

I. Thiopental control group (TP control, $\mathrm{n}=5$ ): Rats were anesthetized with thiopental sodium $(75 \mathrm{mg} / \mathrm{kg}$, i.p.) (15),

II. Ketamine/xylazine control group ( $\mathrm{K} / \mathrm{X}$ control, $\mathrm{n}=5)$ : Rats were anesthetized with ketamine/xylazine (60/10 mg/kg, i.p.) (16),

III. Thiopental+5-hydroxydecanoate group $(\mathrm{TP}+5-\mathrm{HD}, \mathrm{n}=$ 6): 5-hydroxydecanoate (5-HD, $50 \mathrm{ng} / \mathrm{g}$, i.p.) was administered 5 minutes before the thiopental sodium $(75 \mathrm{mg} / \mathrm{kg}$, i.p.) anesthesia,

IV. Ketamine/xylazine+5-hydroxydecanoate group $(\mathrm{K} / \mathrm{X}+5$ $\mathrm{HD}, \mathrm{n}=6$ ): 5 -hydroxydecanoate (5-HD, $50 \mathrm{ng} / \mathrm{g}$, i.p.) was administered 5 minutes before the ketamine/xylazine $(60 / 10 \mathrm{mg} /$ $\mathrm{kg}$, i.p.) anesthesia.

\section{Statistical analysis}

Statistical evaluation was performed by Graph Pad Software. Data are expressed as mean \pm S.E.M or the percentage of incidence. For repeated measurements, two-way ANOVA was used in hemodynamic parameters. Incidence of arrhythmia was evaluated by Fisher's exact test, $\mathrm{p}<0.05$ was considered to indicate statistical significance.

\section{Results}

The hemodynamic parameters including mean arterial blood pressure (MABP) and heart rate (HR) were monitored during the 10-minute period for the experimental protocol. MABP and HR were not significantly different in TP control and $\mathrm{K} / \mathrm{X}$ control

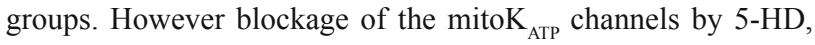
MABP was increased significantly only in TP $+5-\mathrm{HD}$ group when compared to its own control group. But there was no significant difference in MABP between $\mathrm{K} / \mathrm{X}+5-\mathrm{HD}$ and its control group (Fig. 1). Furthermore, blockage of the mitoK ${ }_{\text {ATP }}$ channels by 5-HD caused a decrease in $\mathrm{HR}$ only in $\mathrm{K} / \mathrm{X}+5-\mathrm{HD}$ compared with its control group (Fig. 2).

At the end of the experimental protocol, the arrhythmia parameters were evaluated from ECG records of experiment animals in accordance with the Lambeth conventions (17). The incidence of ventricular ectopic beat (VEB), ventricular tachycardia (VT) and ventricular fibrillation (VF) were determined in each group. Severe arrhytmogenic effects were evaluated with the mitoK $\mathrm{K}_{\text {ATP }}$ channel blocker (Fig. 3). Blockage of mitoK ${ }_{\text {ATP }}$ channels by 5-HD significantly increased the VEB incidence when compared with their control groups. Moreover, the incidence of VEB in TP+5$\mathrm{HD}$ (100 was significantly different from $\mathrm{K} / \mathrm{X}+5$-HD group (66.6 $\%$ ). During the experimental protocol, VT was not observed in TP control, $\mathrm{K} / \mathrm{X}$ control and $\mathrm{K} / \mathrm{X}+5-\mathrm{HD}$ groups. But VT was observed in $\mathrm{TP}+5$-HD group with $88.3 \%$ incidence. VF was not observed in any experimental group.

\section{Discussion}

It is an important to bear in mind that anesthetics which will be used in experimental studies, especially related with cardiovascular system, may affect hemodynamic parameters and arrhythmia scores differently. One of the reasons of this could be that the anesthetic has different effects associated with different mechanisms (i.e. mitoK $_{\text {ATP }}$ channel, oxidative stress). This may explain the inconsistent results in many articles in the literature.

Oxidative stress results from imbalance between oxidants and antioxidants in favor of the oxidants (18). It causes excessive production of reactive oxygen species (ROS). Indeed, redox signaling has regulatory role on several physiological processes in the heart (i.e. excitation-contraction coupling) (19). However, excess accumulation of ROS induces a chain of reactions in cardiovascular pathological processes such as hypertension, ischemia/reperfusion injury (20). It has been reported that markers of oxidative stress (such as malondialdehyde, superoxide dismutase and catalase) are affected by ketamine and thiopental to different degrees (21). 


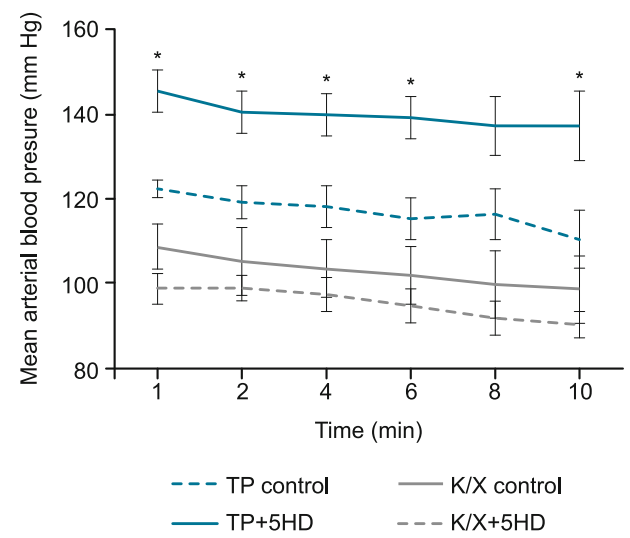

Fig. 1. Changes in mean arterial blood pressure in TP control $(n=5), K / X$ control $(n=5), T P+5-H D(n=6)$ and $K / X+5-H D(n=6)$ groups during the 10 -minute experimental protocol. ${ }^{*} \mathrm{p}<0.05$ compared with TP control.

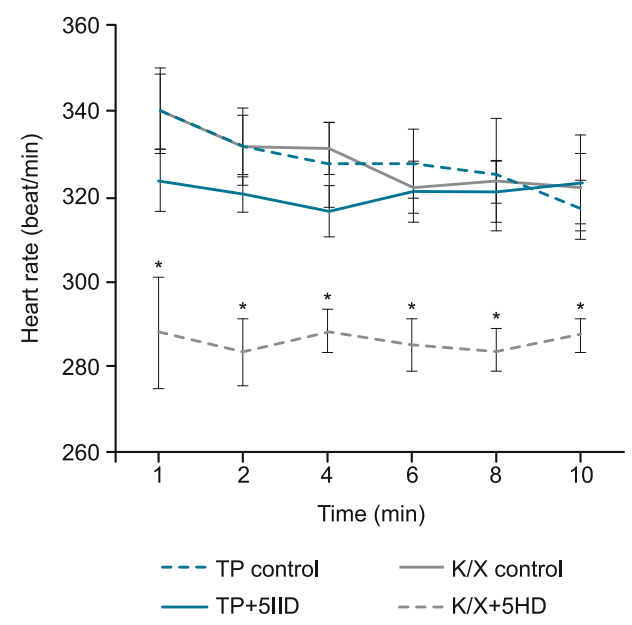

Fig. 2. Changes in heart rate in TP control $(n=5), K / X$ control $(n=5)$, $\mathrm{TP}+5-\mathrm{HD}(\mathrm{n}=6)$ and $\mathrm{K} / \mathrm{X}+5-\mathrm{HD}(\mathrm{n}=6)$ groups during the 10 -minute experimental protocol. $* \mathrm{p}<0.05$ vs compared with $\mathrm{K} / \mathrm{X}$ control.

Mitochondria is the main target and end effector for a number of cellular metabolic processes including cell-signaling cascades, redox control, ion homeostasis and cell death. Mitochondria are important in relation to oxidative stress because it is the main source for pathological ROS production (22). It has also been known that impaired mitochondrial function is the most important reason of reperfusion injury, e.g. apoptosis, necrosis and cell death (23). That is why mitochondria is the main target of protective interventions against reperfusion injury. Impairment of cardiac mitochondrial function after ischemia or ischemia/reperfusion causes a decrease in the adenine nucleotide content of myocytes, impairment in the adenine nucleotide translocase activity, depression of the respiratory chain complex activity, attenuation in membrane potential and decrease in NADH dehydrogenase activity (23-28). Considering all this energy related changes in reperfusion injury, opening of the mitoK $_{\text {ATP }}$ channels seems to be important to protect the heart. It has already been reported that mitoK $_{\mathrm{ATP}}$ channels in the heart play an important role in protective effects of preconditioning against

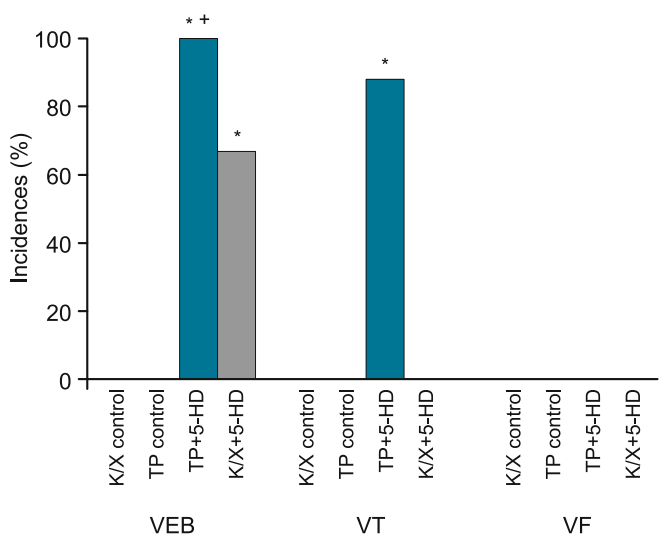

Fig. 3. Changes in arrhythmia incidence (\%, ventricular ectopic beat, tachycardia and fibrilation) during the 10-minute experimental protocol in TP control $(n=5), K / X$ control $(n=5), T P+5-H D(n=6)$ and $\mathrm{K} / \mathrm{X}+5-\mathrm{HD}(\mathrm{n}=6)$ groups. *; vs compared with own control, +; vs compared with $\mathrm{K} / \mathrm{X}+5-\mathrm{HD}$ group, $\mathrm{p}<0.05$.

ischemia/reperfusion injury (29-31). The cardioprotection provided by mitoK $_{\text {ATP }}$ channels could be affected by the administered anesthetic in the experimental animal studies.

The present study investigated whether the mitoK $_{\text {ATP }}$ channels have any role on cardiovascular effects of TP or K anesthesia in rats. 5-HD, a specific mitoK ${ }_{\mathrm{ATP}}$ channel blocker, increased MABP only in TP+5-HD group. But 5-HD did not cause any significant change in MABP in $\mathrm{K} / \mathrm{X}+5$-HD group. On the other hand, blockage of mitoK ${ }_{\text {ATP }}$ channels by 5 -HD decreased HR only in $\mathrm{K} / \mathrm{X}+5$-HD group. When the arrhythmia parameters were evaluated in $\mathrm{TP}+5$ $\mathrm{HD}$ and $\mathrm{K} / \mathrm{X}+5-\mathrm{HD}$ groups, there was an increase in arrhythmia parameters, especially in $\mathrm{TP}+5-\mathrm{HD}$ group. There were studies about important role of the mitoK ${ }_{\text {ATP }}$ channels in antiarrhythmic effects of nicorandil, 3-pyridyl pinacidil or exercise against to I/R injury $(32,33)$. Furthermore, it has been demonstrated that increase in mitoK $_{\mathrm{ATP}}$ channel activity by diazoxide in isolated rat cardiomyocytes is inhibited by TP and R-ketamine but not by Sketamine or xylazine (34). The different interaction with mitoK ${ }_{\text {ATP }}$ channels and the anesthetic could reflect hemodynamic parameters.

It has been known that the hemodynamic parameters are closely related with arrhythmia parameters. Thus the severe arrythmogenic effect of TP could be associated with the increase in the MABP when mitoK ${ }_{\mathrm{ATP}}$ channels are blocked. In addition to this, it has been reported that decrease in HR could play a cardioprotective role against ischemia/reperfusion injury (35). Similarly in the present study, 5-HD induced decrease in $\mathrm{HR}$ in $\mathrm{K} / \mathrm{X}+5$-HD group may cause cardioprotection in arrhythmia scores.

In conclusion, mitoK $_{\mathrm{ATP}}$ channels that play important role in cardioprotection have also effects on $\mathrm{K}$ and $\mathrm{T}$ anesthesia. The present investigation has shown the first time to the best of our knowledge, mitoK $_{\text {ATP }}$ channels blockage by 5-HD differently reflected the hemodynamic parameters and arrhythmia scores dependent on the anesthesia type: K or TP. So, it is one of the important steps to select the right anesthetic for cardiovascular experimental studies, especially for those including mitoK $_{\text {ATP }}$ channels because of the different interaction of $\mathrm{K}$ or TP with mitoK $_{\text {ATP }}$ channels. 


\section{References}

1. Bertens APMG, Booij LHDJ, Flecknell PA, Lagerweij E. Anesthesia, Analgesia and Euthanasia. In: L.F.M. Van Zutphen, V. Baumans, A.C. Beynen, eds. Principles of Laboratory Animal Science. Oxford: Elsevier Science, 2001.

2. Kayaalp SO. Genel Anestezinin Farmakolojik Yönü ve Genel Anestezikler. In: Rasyonel Tedavi Yönünden Tibbi Farmakoloji. Ankara: Hacettepe-Tas; 2000, 780-783.

3. Grover GJ, McCullough JR, D’Alonzo AJ, Sargent CA, Atwal KS. Cardioprotective profile of the cardiac-selective ATP-sensitive potassium channel opener BMS-180448. J Cardiovasc Pharmacol 1995; 25: 40-50.

4. Garlid KD. On The Mechanism of Regulation of The Mitochondrial $\mathrm{K}^{+} / \mathrm{H}^{+}$Exchanger. J Biol Chem 1980; 255: 11 273-11 279.

5. Marinovic J, Bosnjak ZJ, Stadnicka A. Distinct roles for sarcolemmal and mitochondrial adenosine triphosphate-sensitive potassium channels in isoflurane-induced protection against oxidative stress. Anesthesiology 2006; 105: 98-104

6. Garlid KD. Opening Mitochondrial $\mathrm{K}_{\mathrm{ATP}}$ In The Heart - What Happens, And What Does Not Happen. Basic Res Cardiol 2000; 95: 275-279.

7. Dos Santos P, Kowaltowski AJ, Laclau MN, Seetharaman S, Paucek P, Boudina S et al. Mechanisms By Which Opening The Mitochondrial ATP-Sensitive $\mathrm{K}^{+}$Channel Protects The Ischemic Heart. Am J Physiol Heart Circulat Physiol 2002; 283: H284-295.

8. Hausenloy DJ, Maddock HL, Baxter GF, Yellon DM. Inhibiting Mitochondrial Permeability Transition Pore Opening: A New Paradigm For Myocardial Preconditioning? Cardiovasc Res 2002; 55: 534-543.

9. Muravyeva M, Sedlic F, Dolan N, Bosnjak ZJ, Stadnicka A. Preconditioning by isoflurane elicits mitochondrial protective mechanisms independent of sarcolemmal KATP channel in mouse cardiomyocytes. J Cardiovasc Pharmacol 2013; 61: 369-77.

10. Kaasik A, Safiulina D, Zharkovsky A, Veksler V. Regulation Of Mitochondrial Matrix Volume. Am J Physiol Cell Physiol 2007; 292: C157-163.

11. Szewczyk A, Wojtczak L. Mitochondria As A Pharmacological Target. Pharmacol Rev 2002; 54: 101-127.

12. Tanno M, Miura T, Tsuchida A, Miki T, Nishino Y, Ohnuma Y, Shimamoto K. Contribution of Both The Sarcolemmal $\mathrm{K}_{\mathrm{ATP}}$ And Mitochondrial $\mathrm{K}_{\text {ATP }}$ Channels To Infarct Size Limitation By $\mathrm{K}_{\text {ATP }}$ Channel Openers: Differences From Preconditioning In The Role Of Sarcolemmal $\mathrm{K}_{\text {ATP }}$ Channels. Naunyn-Schmiedeberg's Arch Pharmacol 2001; 364: 226-232.

13. Testai L, Rapposelli S, Calderone V. Cardiac ATP-Sensitive Potassium Channels: A Potential Target For An Anti-Ischaemic Pharmacological Strategy. Cardiovasc Hematol Agents Med Chem 2007; 5: 79-90.

14. Vajda S, Baczkó I, Leprán I. Selective Cardiac Plasma-Membrane $K_{\text {ATP }}$ Channel Inhibition Is Defibrillatory And Improves Survival During Acute Myocardial Ischemia And Reperfusion. Eur J Pharmacol 2007; 577: 115-123.

15. Tecder-Unal M, Kanzik Y. Peroxynitrite in reperfusion arrhythmias and its whole blood chemiluminescenceresults. Pharmacol Res 2004; 49: $7-16$.

16. ErgünY,DarendeliS,ImrekS,KilinçM,OksïzH. The comparison of the effects of anesthetic doses of ketamine, propofol, and etomidate on ischemia-reperfusion injury in skeletal muscle. Fundam Clin Pharmacol 2010;24: 215-22.

17. Walker MJA, Curtis MJ, Hearse DJ, Campbell RWF, Janse MJ, Yellon DM et al. TheLambeth Conventions: guidelines for the study of arrhythmias in ischaemia, infarction and reperfusion. Cardiovasc Res 1988; 22: 447-455.
18. Sies H. Oxidative stress: oxidants and antioxidants. Exp Physiol 1997; 82: 291-295.

19. Burgoyne JR, Mongue-Din H, Eaton P, Shah AM. Redox signaling in cardiac physiology and pathology. Circ Res 2012; 111 (8): 1091-1106.

20. Ginter E, Simko V, Panakova V. Antioxidants in health and disease. Bratisl Med J 2014; 115 (10): 603-606.

21. Yildiz H, Coskuner I, Bulbuloglu E, Silay E, Kurutas EB, Dogan $\mathbf{Z}$ et al. The protective effects of ketamine and propofol in obstructive jaundice: an experimental study. Bratisl Med J 2012; 113 (3): 139-144.

22. Agarwal B, Stowe DF, Dash RK, Bosnjak ZJ, Camara AK. Mitochondrial targets for volatile anesthetics against cardiac ischemia-reperfusion injury. Front Physiol 2014; 5: 341

23. Suleimana MS, Halestrap AP, Griffithsa EJ. Mitochondria: a target for myocardial protection. Pharmacol Therap 2001; 89: 29-46.

24. Rouslin W. Protonic inhibition of the mitochondrial oligomycin sensitive adenosine-5-triphosphate in ischemic and autolyzing cardiac muscle. J Biol Chem 1983; 258: 9657-9661.

25. Di Lisa F, Menabo R, Siliprandi N. L-propyonil-carnitine protection of mitochondria in ischemic rat hearts. Mol Cell Biochem 1989; 88: 169-173.

26. Hardy DL, Clark JB, Darley-Usmar V, Smith DR, Stone D. Reoxygenation dependent decrease in mitochondrial NADH CoQreductase (complex I) activity in the hypoxic-reoxygenated rat heart. Biochem J 1991; 274: 133-137.

27. Veitch K, Hombroeckx A, Caucheteux D, Poleur H, Hue L. Global-ischemia induces a biphasic response of the mitochondrial respiratory chain. Anoxic pre-perfusion protects against ischemic damage. Biochem J 1992; 281: 709-715.

28. Griffiths EJ, Halestrap AP. Mitochondrial non-specific pores remain closed during cardiac ischaemia but open upon reperfusion. Biochem $\mathrm{J}$ 1995; 307: 93-98.

29. O'Rourke B. Evidence for mitochondrial $\mathrm{K}+$ channels and their role in cardioprotection. Circulat Res 2004; 94: 420-432.

30. Rajesh KG, Sasaguri S, Suzuki R, Xing Y, Maeda H. Ischemic preconditioning prevents reperfusion heart injury in cardiac hypertrophy by activation of mitochondrial KATP channels. Int J Cardiol 2004; 96: 41-49.

31. Vegh A, Parratt JR. The role of mitochondrial K(ATP) channels in antiarrhythmic effects of ischaemic preconditioning in dogs. Br J Pharmacol 2002; 137: 1107-1115.

32. Das B, Sarkar C. Selective mitochondrial KATP channel activation by nicorandil and 3-pyridyl pinacidil results in antiarrhythmic effect in an anesthetized rabbit model of myocardial ischemia/reperfusion. Methods Find Exp Clin Pharmacol 2003; 25: 97-110.

33. Quindry JC, Schreiber L, Hosick P, Wrieden J, Irwin JM, Hoyt E. Mitochondrial KATP channel inhibition blunts arrhythmia protection in ischemic exercised hearts. Am J Physiol Heart Circulat Physiol 2010; 299: H175-83.

34. Zaugg M, Lucchinetti E, Spahn DR, Pasch T, Garcia C, Schaub MC. Differential effects of anesthetics on mitochondrial K(ATP) channel activity and cardiomyocyte protection. Anesthesiology 2002; 97: 15-23.

35. Kano S, Ichihara K, Komatsu K, Satoh K. Comparative effects of azelnidipine and amlodipine on myocardial function and mortality after ischemia/reperfusion in dogs. J Pharmacol Sci 2011; 116: 181-187.

Received November 18, 2014. Accepted November 27, 2014. 